\title{
Incorporating Freehand Sketches and Mockups into Senior Design Capstone Course: Case Study with a Hand Cycle Vehicle Rack
}

Faculty: Richard W. Marklin, Jr. and Vikram Cariapa

Students: Peter Schneider, Beau Backhaus, Sam Dieckhaus, Brandon Bork, Adam Fettig

Department of Mechanical Engineering

Marquette University, Milwaukee, WI

Richard.marklin@marquette.edu, Vikram.cariapa@marquette.edu,

\begin{abstract}
From the students' perspective, the project objective of this 2-semester senior design course was to design and build a storage device for a hand powered upright hand cycle that can be installed on the exterior of a wheelchair accessible Dodge-Chrysler minivan so that a person with paraplegia or quadriplegia can drive the vehicle independently (without a human aide) when the hand cycle is loaded on the vehicle.

The novelty of this paper is the pedagogy of blending traditional methods of engineering design (hand sketches, low resolution mockups, and prototypes) along with CAD design and modern computational analytics, including FEA, in a 2-semester design course. Students drew sketches of multiple ideas and made a full-size three dimensional mockup of the rear of a Chrysler minivan out of plywood and structural wood. They also made two mockups and two metal prototypes and analyzed the design with FEA.

Course evaluations from students revealed their appreciation for having the opportunity to hand sketch ideas and make low resolution mockups in the first semester to arrive at a general design. (The second semester was devoted to detailed design and making functional prototypes.) The students felt that they had a rich design experience that they could use for future design projects in their careers.
\end{abstract}

\section{Background}

The end product of this senior capstone project is a functional storage rack for a hand-powered 3wheeled cycle for a minivan so that that a person who cannot use his/her legs (such as with paraplegia or quadriplegia) can travel independently without the assistance of a human aide. This project was initiated by the Veterans Administration Hospital in Milwaukee, WI, and the team worked with local companies that provided technical and manufacturing expertise. Five undergraduate engineering students from Marquette University College of Engineering designed and made mockups and prototypes of the one piece storage rack that weighs less than $35 \mathrm{lbs}$.

Currently no exterior rack for a hand-powered cycle for a minivan exists, so a user has to have an able-bodied assistant travel with him/her all the time in the van because the hand cycle is stored 
inside the vehicle, which prevents the user from exiting the vehicle (unless the hand cycle is removed by the aide). This exterior storage rack for a hand cycle allows a user to drive the van independently (without an aide) to locations to participate in cycle rides. The user has more opportunities to ride the cycle for critical exercise, thus improving the overall health and lowering care cost of the user and health care providers

\section{Design}

The final design of the storage rack is shown in Figure 3 (Prototype 2). Figures 1 and 2 show Prototype 1, and the second mockup is revealed in Figure 4.

The storage rack uses an electric winch with a remote control to lift and lower the hand cycle on the rear door of the minivan for safe and secure storage. The winch allows an assistant with low physical strength (1st percentile female) to load and unload the hand cycle on the minivan. Plastic wheel wells from Saris Inc. (Madison, WI) hold the rear wheels securely when the hand cycle is mounted on the vehicle. In addition to fabric support straps, a steel-reinforced strap attaches the hand cycle and rack to the inside of the van to minimize the risk of theft.

The storage rack was designed by the undergraduate senior engineering students using handdrawn sketches, which is a traditional ideation and design process promoted by ASEE in the $1950 \mathrm{~s}^{1}$. Prof. Richard Marklin led the students, who made hand drawn sketches to generate many ideas (>100). The ideas culminated in a full size wooden mockup of the rear end of the van and a mockup of the storage rack made of PVC pipe and assorted hardware in Dec. 2013 (Figure 4). In the 2014 Spring semester, the students made two prototypes (Prototype 1 in Figures 1 and 2 and Prototype 2 in Figure 3). The prototypes are based on CAD drawings and computational analytics, including finite element analysis (FEA). The second prototype was made of powder coated etched aluminum square channel with appropriately designed winch, straps, wheel wells, and supports. This prototype looks and functions like a commercial product, and the design has potential for commercialization.

\section{Discussion}

In this project students used the traditional methods of engineering design espoused by ASEE since the $1950 \mathrm{~s}^{1}$, which include hand-drawn sketches, full-size mockups made of basic materials such as wood and plastic, and prototypes. Students made a full-size three dimensional mockup of the rear of a Chrysler minivan out of plywood and structural wood, complete with a bumper, sides, roof, and functional door. They also made 2 mockups (one wood and one PVC (Figure 4)) of the storage rack, which improved the design substantially. Two metal prototypes were made in the second semester, Spring 2014 (Figures 1, 2, and 3).

In some engineering curricula in the U.S., engineering students do not have the opportunity to make mockups and prototypes because they are not allowed to use University machine shops or they do not know how to use tools and equipment. The Marquette U. Opus College of 
Engineering has a new building (Engineering Hall) that has a Discovery Learning Laboratory (DLL) that provides all engineering students with the facilities, equipment, and technical staff so students can make their designs out of any material - metal, composites, plastic, wood, and 3-d printing. All project teams in the senior capstone course, under the direction of Prof. Vikram Cariapa, are required to make physical mockups and/or prototypes of their final designs.

Students have used the DLL facilities extensively since Engineering Hall opened three years ago.

Lessons learned from making mockups are the following:

- Mockups should be quick, low resolution structures that show the full-size, general shape, and basic function of the design. Typical materials are $2 x 4 s$, plywood, foam board, corrugated board, etc. A mockup should not take more than one or two days to make.

- $\quad$ The faculty advisor should work with the students building the first mockup. The tendency of students is to make a detailed, high resolution structure that may take many hours of machining and fabricating. Mockups should be quick and low resolution. After the students learn how to make a mockup, then they can normally make the subsequent mockups without faculty help.

Students drew over 100 pencil sketches of their ideas early in the Fall 2013 semester as part of the ideation stage. Prof. Marklin told the students that the quality of the sketches did not matter as the idea was more important. The students had not taken a sketching course prior and were apprehensive about sketching. However, after assurance and encouragement from Prof. Marklin, the students were able to draw with enough visual fidelity to convey their ideas.

Lessons learned from the sketching phase are the following:

- Only one idea sketched on one piece of 8.5 x 11 in. blank white paper. Fill at least half of the paper with the sketch (no tiny sketches).

- Only a wooden pencil is allowed to sketch idea (no mechanical pencils as the lead breaks too easily). No rulers, straightedges, and protractors.

- The faculty advisor should strongly mention that the quality of the sketch is not important -- engineers are not artists. The purpose of each sketch is to visually convey an idea, and not create art.

- Sketches should be done quickly ( $<5 \mathrm{~min}$ ) in order to put the focus on the idea and not on the artistic quality of the drawing.

The skill to visually represent ideas with hand-drawn sketches has been neglected in engineering curricula for over 20 years, since the prevalence of CAD. Research has shown that students who hand sketched ideas, rather than relying only on CAD drawings, produced higher quality design projects ${ }^{2-5}$. Professor. Marklin teaches a class that instructs engineering students, regardless of visual art talent, how to sketch ideas with only a pencil (no instruments such as rulers, triangles, etc.). Assessed results from the sketching class have been positive and were published at the 2013 ASEE conference 6 .

It is important for the faculty advisor to stress in the class that the most important part of the capstone project is learning the process for design. Although the final outcome in the course is 
important (final prototype), it is not as important as learning the design process, which the students can employ throughout their careers. Assessment from students revealed their appreciation for having the opportunity to hand sketch ideas and make low resolution mockups in the first semester to arrive at a general design, and then focus on the detailed design and making prototypes in the second semester.

\section{Acknowledgments}

Veterans Administration (VA) Hospital, Milwaukee, WI

Saris Inc., Madison, WI

Tankcraft Corp., Darien, WI

Milwaukee Tool Corp., Brookfield, WI

\section{Bibliography}

1. ASEE (American Society for Engineering Education) (1955). Report of the committee on evaluation of engineering education. Journal of Engineering Education, Vol. 46, 25-60.

2. Sorby, S.A. (2009). Educational research in developing 3D spatial skills for engineering students. International Journal of Science Education. Vol. 31, No. 3, Feb. 1, 2009, pp 459-480.

3. Ullman, D., Wood, S., and Craig, D. (1990). The importance of drawing in the mechanical design process. Computation and Graphics, Vol. 14, No. 2, 263-274.3.

4. Schutze, M., Sachse, P., and Romer, A. (2003). Support value of sketching in the design process. Research in Engineering Design. Vol. 14, 89-97.

5. Yang, M. (2009). Observations on concept generation and sketching in engineering design. Research in Engineering Design. Vol. 20, 1-11.6.

6. Marklin, R., Goldberg, J., and Nagurka, M. (2013). Freehand sketching for engineers: A pilot study. 120th American Society of Engineering Educators (ASEE) Annual Conference and Exposition. June 23-26, Atlanta, GA. 


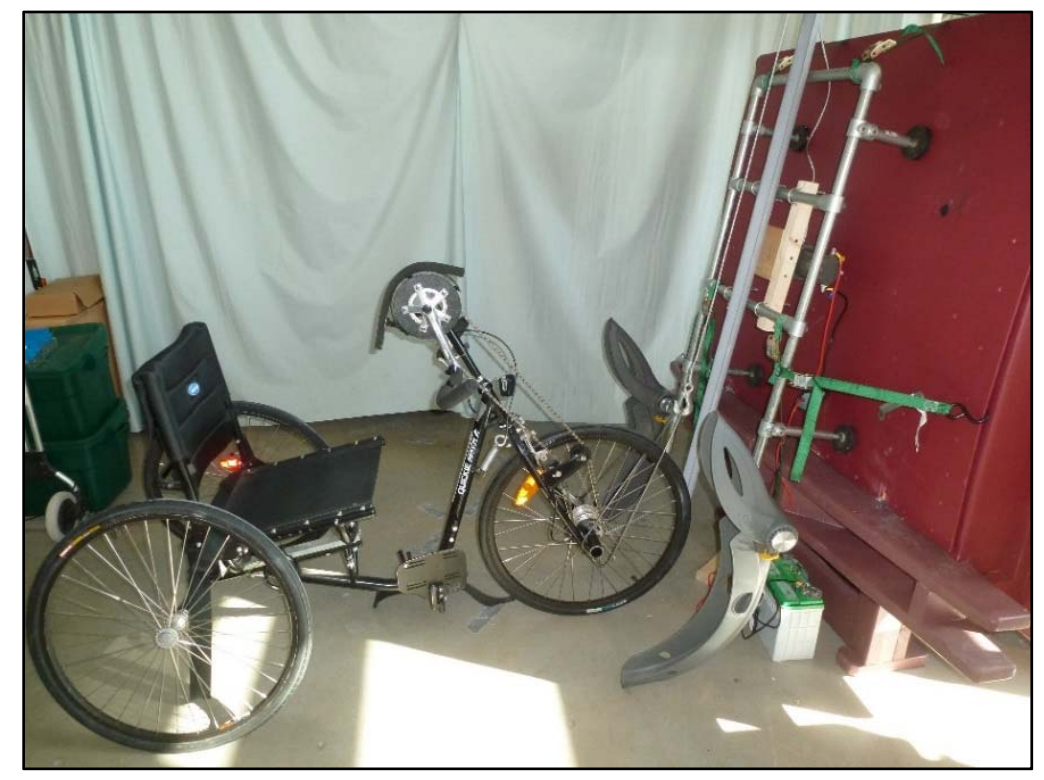

Figure 1. Prototype 1 - hand cycle ready for loading on the rack (Feb. 2014). A full-size mockup of the rear of a Chrysler minivan is shown is the red structure on the right. The rack is mounted to the rear door with six straps. The rack's center rail and plastic wheel wells from Saris Inc. (Madison, WI) support the front and rear wheels, respectively. This prototype was made with iron water pipe and connectors with threads and Allen screws.

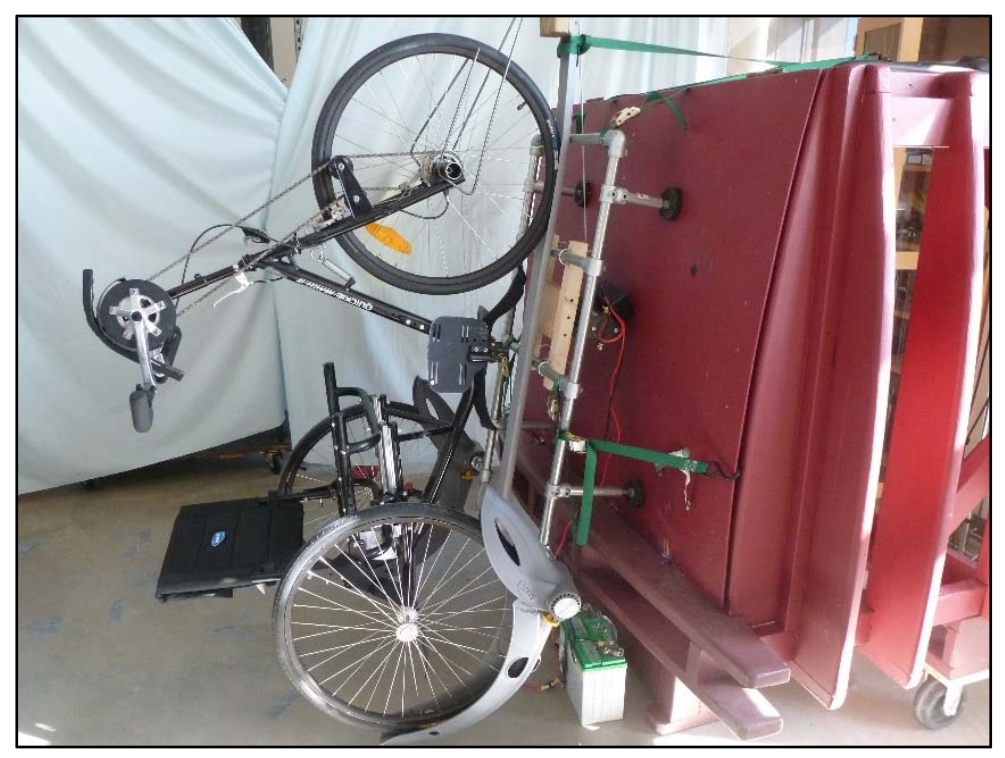

Figure 2. Prototype 1 - hand cycle loaded on the rack attached to the minivan rear door (Feb. 2014). Hand cycle was lifted with a pulley and electric winch, attached to the wood 2x4s in the center of the rack. Wheel wells were raised to securely hold the rear wheels. 


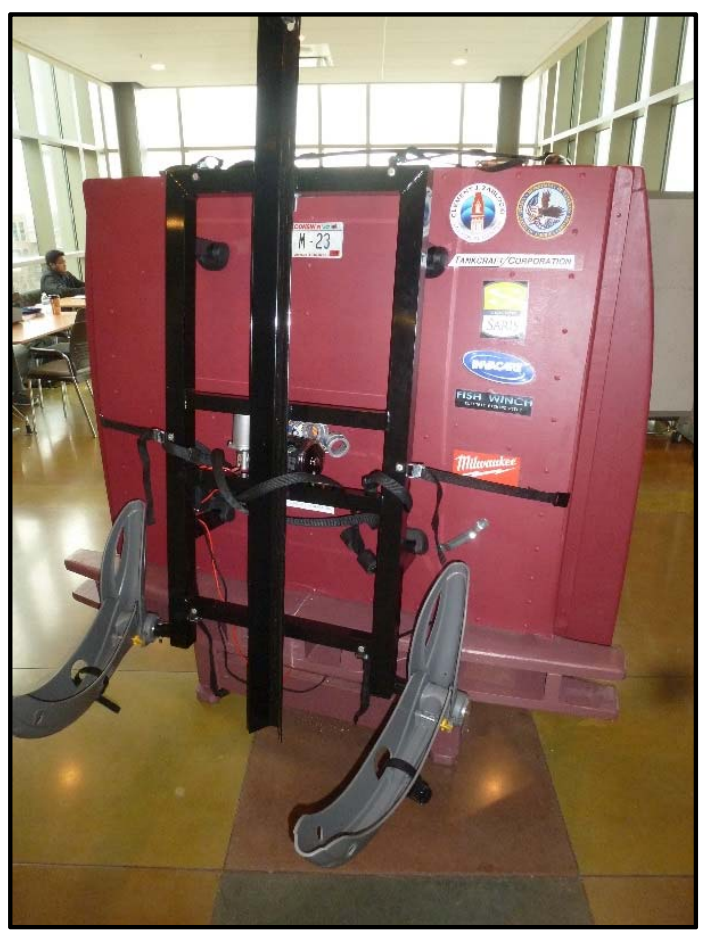

Figure 3. Prototype 2 (final) of storage rack for hand cycle attached to a full-size mockup of a Chrysler minivan (April 2014). The rack was made of 2 in. square aluminum channel welded at the joints. The aluminum was etched and then powder coated. The rack and its components weighed $35 \mathrm{lbs}$. The plastic wheel wells are from Saris Inc. (Madison, WI).

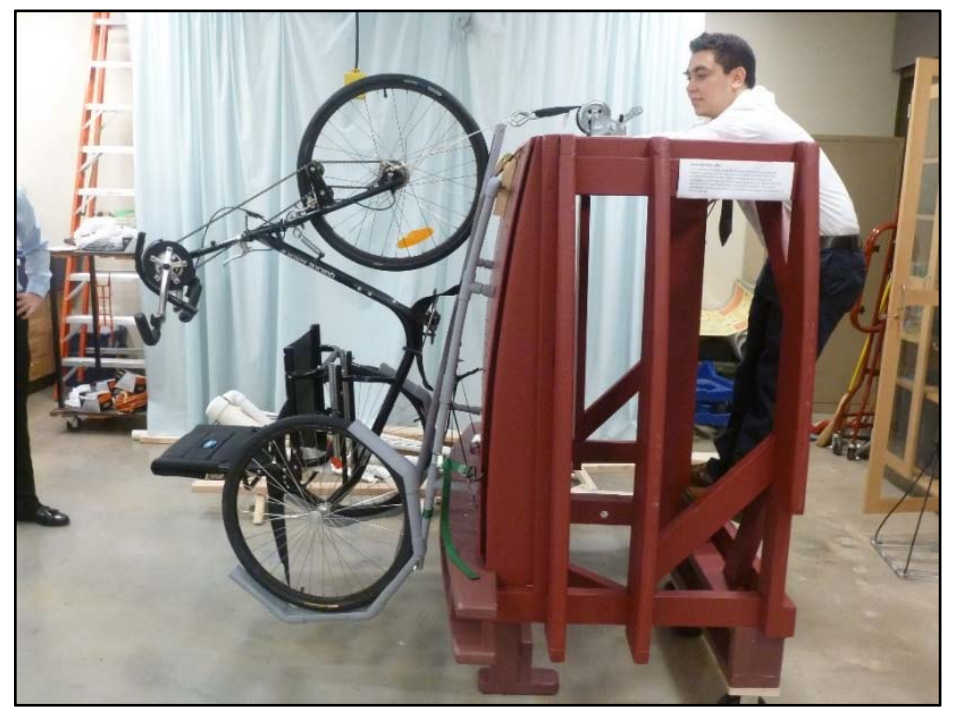

Figure 4. Mockup 2 of mockup of minivan rear with hand cycle attached to the rear door (Dec. 2013). In this mockup, a student lifts the hand cycle with a hand winch, and wheel wells hold the rear wheels securely. This mockup was made of PVC pipe glued with conventional plumbing connectors and was spray painted grey. 